\title{
An Investigation into the Level of Burnout in Secondary School English Language Teachers and their Perception of Prevention of it
}

\author{
* Ziaullah, MPhil Scholar \\ ** Dr. Farooq Nawaz Khan, Assistant Professor (Corresponding Author) \\ *** Dr. Shazia Kanwal, Principal
}

\begin{abstract}
Research on burnout gained popularity in the 1970s but in the last three decades' research about burnout gained immense popularity (Hedden, 2005, Harmesh, Laurenz, Maulana \& Veen., 2018). Frudenberger (1974) defined the term (Burnout) for the first time who opined that when there are too many professional demands with limited resources and rewards, it causes a sense of chronic stress and failure. The current research study was undertaken to find out the level of burnout among secondary school English teacher and also their perception of prevention from burnout. The data from the respondents were collected through CBI inventory to measure their level of burnout and its effects on teachers at the secondary school level in district Swat. An open-ended 7 items questionnaire was used to identify the perception of the teachers about preventing them from burning out. The population for this study is comprised of government secondary schools' teachers (230) male-only from which the sample group was selected through systematic sampling techniques. The reliability coefficient was measured through the Cronbach alpha method the $=.00000$. All the respondents used the categories indicating a low level of burnout and the average score of all the respondents is below 40 in most of the categories of burnout. The study recommends that the school management should take preventive measures to help teachers fight burnout on a school level and larger scale (directorate level) organizations should help teachers maintain balance in their work so that they do not fall victim to burnout. The study is of immense importance for the wellbeing of the teachers and the effective teaching-learning process. To be able to generalize the findings of the study, it is recommended for future researchers to undertake it on a larger scale such as provincial or country level. Moreover, the current research has been conducted only among male secondary school teachers. It would be interesting to see the research-based results across both genders.
\end{abstract}

Keywords: Burnout, Secondary School Teachers', Perception, Burnout Prevention

Introduction

According to Dworkin (1986) and Farber (1991), there is no universal definition of Burn out. Maslach and Leiter (1998) declared burnout as a specific threat for the professionals who are engaged with their clients in some capacity that causes depersonalization, reduced personal accomplishments, and emotional exhaustion. Although it is very difficult to find a universal definition of burnout, Maslach (1986) definition is the most commonly accepted. It is conceptualized to be a long-lasting and recurrent reaction to feelings of low accomplishment and utmost pressures, depersonalization of colleagues and clients in the work context, and emotional exhaustion. Dougherty (1993) stated various concepts of burnout as, "a) to become exhausted, fail or wear out, b) loss of creativity, c) losing dedication for work; d) and drifting apart from clients, job and workplace; e) a reaction to the persistent stress of making it to the top; and f) a syndrome of attitude which is inappropriate towards clients and self, often linked with uncomfortable emotional and physical symptoms" (p 623). Hargeaves (1978) depicts burnout as similar to a progressively outrageous aftereffect of long-term pressure prompting all-out fatigue, lack of care, distance from work, and withdrawal into various

\footnotetext{
* Center for Education and Staff Training University of Swat, Khyber Pakhtunkhwa, Pakistan. Email: saadu002@gmail.com

** Center for Education and Staff Training University of Swat, Khyber Pakhtunkhwa, Pakistan. Email: farooqlit76@gmail.com

*** Elementary and Secondary Education Khyber Pakhtunkhwa Pkistan Email: shaziamd09@ gmail.com
} 
cautious techniques. Burnout is a sort of long term ceaseless reaction to continuous effects of work pressure (Blase, 1982). This is not the same as momentary pressure; intense and lasting pressure is undeniably increasingly serious and alludes to the negative working conditions when occupation stress gives off an impression of being unavoidable to the individual. According to Pines and Aronson (1988), burnout is not limited only to the professions which require human services but it also includes physical symptoms. They further elaborate when the situation demanding long-tern involvement create physical, mental al and emotional exhaustion (p.10) Though, these definitions address some areas of burnout, but these are not clear as O'Discroll (2000) says "It confused burnout usually with different but related variables, especially chronic fatigue and depression" (p 4).

It is also necessary to make difference between burnout, stress, chronic fatigue, and depression, related to one another in one way or another. The problem of burnout is related to the work environment and stress and depression are related to every walk of life. Furthermore, burnout is an occupational vulnerability for various jobs where there is too much involvement with humans.

Burnout research gained popularity in the 1970s but later researchers showed broader similarity in defining burnout. Jackson and Maslach (1981) gave concepts of three basic elements, depersonalization, emotional exhaustion, and reduced personal accomplishment, and stated that emotional exhaustion is the most dominant trait of burnout. Jackson (1981) considered workload and conflict with colleagues as the main sources. In such situations, the worker feels broken, drained, and frustrated. As a result, it deals with people as objects, not humans. The worker feels as the clients consider him responsible for their problems. The worker turns impatient and often is careless about the students, and uncaring towards his/her job and responsibilities.

Besides the consensus on the above-mentioned three core symptoms of burnout, there is a difference in the views of various researchers over cynicism and professional efficacy as Lee and Ashforth (1993) suggest these components (elements) may be treated as separate variables. Dewe, Cooper, and O'Driscoll, (2001) also state Maslach contended that the phenomenon of burnout should be used only for professions that involve human services. Some of the researchers divided emotional exhaustion into emotional and physical exhaustion. When a person is physically exhausted, he feels weakness, chronic fatigue, and low variety and when some feel emotionally exhausted, he/she considers him/herself helpless, the sense of hopelessness and finally develops negative feelings about her/himself and his job.

As stated the terms burnout and stress has been used frequently synonymous, most of the research is also done in overlap without distinguishing each phenomenon from the other and so it created complications and confusion. Teachers use burnout commonly to illustrate everything from failure to alarming administrators to caution over troublesome students (Gold \& Roth, 1993). In the teaching profession, burnout may lead to feelings of indifference, detachment from the job, and several alienation strategies like apathetic, unenthusiastic behavior to the students, using disparaging labels and physical aloofness, and tuning out students through physical departure (Travers \& Cooper, 1996).

According to Leiter and Durup (1994), burnout is an issue that is particularly related to the work atmosphere; on the other hand, depression tends to spread through every walk of a person's life. This research has provided pragmatic support to the views that burnout is situation and job-specific, in contrast to depression which is free of particular circumstances.

Different researchers identified different sources for burnout in teachers. According to Farrell (2003) School's responsibility, workload among beginning teachers (Singh, 1996), management problems (Tomic, 2000), negative school environment (Grayson, 2008), administrative support, students' behavior, and poor job resources (Baker \& Schaufeli, 2006).

Burnout creates negative effects on the teaching-learning process and demotivates the teachers and learners. It has many causes and ultimately negative outcomes too.

\section{Research Objectives:}

1) To identify burnout level among secondary school teachers

2) To investigate the effects of burnout on students' achievement and secondary school teachers' performance.

3) To find out perceptions of secondary school teachers for preventing them from burnout.

Research Questions

1. What is the level of burnout in English language teachers? 
2. How does burnout affect the achievement of secondary school English language teachers and learners?

3. What are English language teachers' expectations of preventing them from burnout?

\section{Methodology and Procedure}

This study was conducted following a quantitative descriptive research design. The data from the respondents were collected through CBI inventory to measure their level of burnout and its effects on teachers at the secondary school level in district Swat. An open-ended 7 items questionnaire was used to identify the perception of the teachers about preventing them from burning out. The population for this study is comprised of government secondary schools' teachers (230) from which the sample group was selected through systematic sampling techniques. The current research study is limited to male-only schools as due to cultural constraints it is difficult for the researcher to collect data from female schools. Furthermore, the CBI was contextualized through conducting pilot testing of the inventory, and reliability co-efficient was measured through the Cronbach alpha method the $=.00000$. Likewise, after the finalization of the inventory, the data normalization was conducted following the skewness and kurtosis method. After the data normal test, all the collected data were analyzed through descriptive and inferential statistics.

\section{Measurement of Burnout}

Researchers noted several conceptual and methodological issues in the Maslach Burnout inventory but still, this inventory is the most popular and extensively used for measuring burnout in different professions. There are certain limitations in the measurement and definition of burnout, and there are also problems in the understandability of its items in various cultural groups. Moreover, the items included in this inventory are specifically limited to the people-oriented occupations. Accordingly, Halbesleben and Demerouti (2005); and Shirom, (2005) stated in this regard that depersonalize and personal accomplishment usually measured by this do not pertain to burnout syndromes. Researchers and critics, therefore, urged for alternative measurement tools of burnout.

The Copenhagen Burnout Inventory (CBI) is a public and new burnout instrument designed to measure burnout and overcome the limitations of MBI. It is measuring the three sub-dimensions with a 19 items questionnaire. It measures psychological and physical fatigue with six items of personal burnout scale, irrespective of individual participation in work. Work-related psychological and physical fatigue is measured by seven items burnout scale. The client elated six items scale measure psychological and physical fatigue experienced by people who work with clients in some capacity. According to Winwood and Winwood (2004) \& Kristensen (2005), the three scales of CBI have shown better criterion-related validity and reliability in different studies conducted in Australia and Denmark. The results of Campos, Carlotto, and Maroco (2013) also support Kristensen et al (2005) suggestion that CBI can be used in the broader context than originally proposed.

\section{Analysis}

Table 1. CBI Scale of personal Burnout, response categories, and scoring.

\begin{tabular}{|c|c|c|c|c|c|c|c|c|}
\hline category & $100 \%$ & $75 \%$ & $50 \%$ & $25 \%$ & 0\% & Missing & SD & Mean Score \\
\hline Question 1 & 1.9 & 25.7 & 51.7 & 17.2 & 3.5 & & 20.2 & 49.5 \\
\hline Total & 4 & 53 & 108 & 36 & 7 & 1 & & \\
\hline Question 2 & 1.5 & 16.6 & 38.9 & 34.4 & 8.6 & & 16.1 & 40.3 \\
\hline Total & 3 & 34 & 81 & 72 & 18 & 1 & & \\
\hline Question 3 & 0.9 & 13.3 & 40.2 & 29.5 & 16.1 & & 15.1 & 36.8 \\
\hline Total & 2 & 27 & 82 & 60 & 33 & 4 & & \\
\hline Question 4 & 3.2 & 11.4 & 15.3 & 36.9 & 3.2 & & 13.8 & 27.3 \\
\hline Total & 6 & 23 & 31 & 75 & 67 & 7 & & \\
\hline Question 5 & 1.4 & 12.6 & 27.9 & 42.5 & 15.6 & & 15.7 & 41.2 \\
\hline Total & 3 & 25 & 56 & 85 & 31 & 9 & & \\
\hline Question 6 & 0.3 & 2.9 & 12.5 & 46.9 & 37.4 & & 20.9 & 19.7 \\
\hline \multirow[t]{2}{*}{ Total } & & 6 & 25 & 95 & 76 & 7 & & \\
\hline & & & & & $\begin{array}{c}\text { Average } \\
\text { Score }\end{array}$ & & 16.9 & 42.98 \\
\hline
\end{tabular}

Table 2. CBI Scale of Work-related Burnout, response categories, and scoring.

\begin{tabular}{ccccccccc}
\hline Category & $\mathbf{1 0 0 \%}$ & $\mathbf{7 5 \%}$ & $\mathbf{5 0 \%}$ & $\mathbf{2 5 \%}$ & $\mathbf{0 \%}$ & Mean Score & SD & Missing \\
\hline Question 1 & 6.8 & 14.2 & 38.7 & 28.5 & 11.8 & 42.8 & 13.2 & 2 \\
Total & 13 & 29 & 80 & 59 & 24 & & & 2
\end{tabular}




\begin{tabular}{|c|c|c|c|c|c|c|c|c|}
\hline Question 2 & 5.3 & 9.2 & 24.7 & 33.5 & 27.3 & 32.6 & 12.1 & \\
\hline Total & 11 & 19 & 51 & 70 & 57 & & & 2 \\
\hline Question 3 & 5.3 & 11.7 & 32.1 & 34.3 & 16.6 & 38.3 & 12.7 & \\
\hline Total & 11 & 24 & 67 & 71 & 34 & & & 2 \\
\hline Question 4 & 11.7 & 19.6 & 33.3 & 24.2 & 11.2 & 48.6 & 9.2 & \\
\hline Total & 24 & 41 & 69 & 50 & 23 & & & 2 \\
\hline Question 5 & 0.3 & 6.1 & 21.7 & 37.5 & 34.4 & 24.7 & 16.5 & \\
\hline Total & 0 & 13 & 45 & 78 & 71 & & & 2 \\
\hline Question 6 & 0.9 & 5.3 & 8.7 & 39.2 & 45.9 & 18.4 & 20.9 & \\
\hline Total & 1 & 11 & 18 & 81 & 95 & & & 3 \\
\hline Question 7 & 26.7 & 18.1 & 24.4 & 19.6 & 11.2 & 57.5 & 16.2 & \multirow{3}{*}{4} \\
\hline \multirow[t]{2}{*}{ Total } & 56 & 38 & 51 & 41 & 19 & & & \\
\hline & & & \multicolumn{3}{|c|}{$\begin{array}{c}\begin{array}{c}\text { Average } \\
\text { Score }\end{array} \\
\end{array}$} & 37.5 & 14.4 & \\
\hline \multicolumn{9}{|c|}{ able 3. CBI Scale of Client Related Burnout, response categories, and scoring. } \\
\hline Category & $100 \%$ & $75 \%$ & $50 \%$ & $25 \%$ & $\mathbf{0 \%}$ & Mean Score & SD & Missing \\
\hline Question 1 & 2.5 & 7.3 & 32.1 & 37.7 & 20.4 & 33.4 & 15.2 & \\
\hline Total & 5 & 15 & 67 & 78 & 42 & & & 2 \\
\hline Question 2 & 1.2 & 4.1 & 21.4 & 40.3 & 32.7 & 35 & 17.1 & \\
\hline Total & 2 & 8 & 45 & 84 & 68 & & & 2 \\
\hline Question 3 & 5.7 & 9.3 & 31.6 & 33.8 & 19.6 & 36.7 & 12.6 & \\
\hline Total & 11 & 19 & 66 & 70 & 40 & & & 3 \\
\hline Question 4 & 6.7 & 7.3 & 35.1 & 29.4 & 21.5 & 37.3 & 12.8 & \\
\hline Total & 15 & 15 & 73 & 61 & 43 & & & 3 \\
\hline Question 5 & 0.5 & 4.2 & 25.8 & 41.7 & 27.8 & 26.9 & 17.2 & \\
\hline Total & 1 & 8 & 53 & 87 & 58 & & & 2 \\
\hline \multirow[t]{3}{*}{ Question 6} & 1.9 & 7.6 & 27.8 & 37.1 & 25.6 & 30.3 & 14.7 & \\
\hline & 3 & 15 & 58 & 77 & 53 & & & 3 \\
\hline & & & & $\begin{array}{l}\text { Average } \\
\text { Score }\end{array}$ & & 33.26 & 14.9 & \\
\hline
\end{tabular}

\section{Results}

Tables 1, $2 \& 3$ show the level of responses from the respondents about their burnout. All the respondents used the categories indicating a low level of burnout and the average score of all the respondents is below 40 in most of the categories of burnout. The no-respondent rate on each item in all categories is below $3 \%$ which indicates that all the items are easily understandable for the respondents. The mean score for all the questions is below 50 except for question 1 on personal burnout which is 51 but the average score on all the questions is 35.8 which indicates a low level of burnout. Similarly, the mean score for question number 7(Do you have enough energy for family and friends during leisure time?) is $\mathbf{5 7}$ but that also shows that most of the respondents get enough energy for their family and have a low level of burnout. The average score for work-related burnout in all questions 37.5 which also indicates a low level of burnout. In the client related category, the mean score for all the questions is below 40 and the average score for this category is 33.26 .

In the open-ended questionnaire, the respondent identified various sources of burnout like lack of support from the principals and administrators, overcrowded classes, workload, unrealistic targets from the government and misbehavior of the student, lack of decision power, the ambiguity of their role as teachers, non-teaching duties, less job recognition and services, undue criticism from the government and society and lack of acknowledgment in the society, grouping, and lack of cooperation of the colleagues enhance their feelings of burnout. They further identified that if the administrators and government-provided them full support and make them autonomous in decision making can prevent them from further stress and burnout. Moreover, they also identified that discussion with colleagues, social and emotional support, recognition of their job, and management of their workload can reduce their burnout. 


\section{Conclusion}

Due to the nature of the profession, teaching will always remain a stressful profession. It is also evident from the responses of the participant that burnout occurs gradually, it is a process, not a single entity. Most of the respondents identified personal and organizational factors responsible for burnout. Therefore, various personal, organizational, and administrative strategies can prevent teachers from burnout. On the personal level positive relationship with colleagues and Principals, adopting a healthier lifestyle, appropriate time management, knowing one's strong and weak points and limitations of the administrators, keeping a balance between personal time and professional time, avoiding perfectionist views, and avoiding overthinking, setting attainable goals and prioritizing it can prevent teachers from burnout. On the other hand, administrators can reduce burnout by providing a conducive environment for teaching, they should engage teachers in forming supportive groups for discussion of apprehensions and should provide support when required. The administrators should arrange regular workshops to implement coping strategies for burnout. They should adopt a mechanism of rewards to motivate the teachers and recognize their efforts and make them autonomous for decision making. Various research studies also identified similar strategies for the prevention of burnout and increasing the efficiency of teachers.

The results indicated that the score on subscales CBI burnout was not much different from each other. It showed that most of the teachers have a low level of burn out but some are on the borderline to moderate level of burnout on the scales and they identified lack of accomplishment and shown de-alienation towards or disengagement with students. It denotes that the teachers can sustain efficient relations with the students and organization and they can concentrate on their job if they are less exhausted emotionally, less stressful and less inhibited by the symptoms. Teachers must comprehend that positive feelings are among the fundamental factors of teaching. The job of a teacher primarily is caring for his/her students. In any case, as it was mentioned in the literature, teaching includes complex student-teacher connections. Accordingly, educators ought to be prepared to painstakingly manage all spaces in the student-teacher connections. Teachers with high burnout levels need to be pre-emptive in keeping discipline in the classroom.

Teachers should adopt such strategies to release stress and prevent burnout. Positive organizational practices can prevent teachers from burnout and will enable them to overcome his/her daily challenges. Due to the scarcity of researches on teachers' burnout in this context this study can be applied with a relatively larger population for confirmation or rejections of its findings. Moreover, the results of this study should be interpreted more cautiously and it has very limited generalization due to its small sample size, small overall population, and focuses on only male secondary school teachers. The focus of this study is Secondary school English teachers so it is recommended that future studies should be carried with diverse subject teachers.

\section{References}

Harmsen, R., Helms-Lorenz, M., Maulana, R., \& van Veen, K. (2018). The relationship between beginning teachers' stress causes, stress responses, teaching behavior, and attrition. Teachers and Teaching, 24(6), 626-643.

Freudenberger, H. J. (1974). Staff burn-out. Journal of social issues, 30(1), 159-165.

Maslach, C., \& Jackson, S. E. (1981). The measurement of experienced burnout. Journal of organizational behavior, 2(2), 99-113.

Dworkin, R. (1986). Autonomy and the demented self. The Milbank Quarterly, 4-16.

Farber, B. A. (1991). Crisis in education: Stress and burnout in the American teacher. Jossey-Bass.

Leiter, M. P., \& Maslach, C. (1998). Burnout. En H. Friedman (Ed.). Encyclopedia of Mental Health.

Maslach, C., Jackson, S. E., Leiter, M. P., Schaufeli, W. B., \& Schwab, R. L. (1986). Maslach burnout inventory (Vol. 21, pp. 3463-3464). Palo Alto, CA: Consulting psychologists press.

Cordes, C. L., \& Dougherty, T. W. (1993). A review and an integration of research on job burnout. Academy of management review, 18(4), 621-656.

Hargreaves, A. (1978). The significance of classroom coping strategies. Sociological Interpretations of Schooling and Classrooms: a reappraisal, 73-100.

Blase, J. J. (1982). A social-psychological grounded theory of teacher stress and burnout. Educational Administration Quarterly, 18(4), 93-113.

O Driscoll, S. W., \& Giori, N. J. (2000). Continuous passive motion (CPM): theory and principles of clinical application. Journal of rehabilitation research and development, 37(2), 179-188. 
Pines, A., \& Aronson, E. (1988). Career burnout: Causes and cures. Free press.

Lee, R. T., \& Ashforth, B. E. (1993). A further examination of managerial burnout: Toward an integrated model. Journal of organizational behavior, 14(1), 3-20.

Cooper, C. L., Cooper, C. P., Dewe, P. J., O'Driscoll, M. P., \& O'Driscoll, M. P. (2001). Organizational stress: A review and critique of theory, research, and applications. Sage.

Gold, Y., \& Roth, R. A. (1993). Teachers managing stress and preventing burnout: The professional health solution. Psychology Press.

Travers, C. J., \& Cooper, C. L. (1996). Teachers under pressure: Stress in the teaching profession. Psychology Press.

Leiter, M. P., \& Durup, J. (1994). The discriminant validity of burnout and depression: A confirmatory factor analytic study. Anxiety, stress, and coping, 7(4), 357-373.

Mavondo, F., \& Farrell, M. (2003). Cultural orientation: its relationship with market orientation, innovation, and organizational performance. Management Decision.

Singh, K., \& Mitchell, W. (1996). Precarious collaboration: Business survival after partners shut down or form new partnerships. Strategic management journal, 17(S1), 99-115.

Brouwers, A., \& Tomic, W. (2000). A longitudinal study of teacher burnout and perceived selfefficacy in classroom management. Teaching and Teacher Education, 16(2), 239-253.

Grayson, J. L., \& Alvarez, H. K. (2008). School climate factors relating to teacher burnout: A mediator model. Teaching and teacher education, 24(5), 1349-1363.

Schaufeli, W. B., Baker, A. A., \& Salanova, M. (2006). Educational and Psychological Measurement. The measurement of work engagement with a short questionnaire. A CrossNational Study, 66(4).

Halbesleben, J. R., \& Demerouti, E. (2005). The construct validity of an alternative measure of burnout: Investigating the English translation of the Oldenburg Burnout Inventory. Work \& Stress, 19(3), 208-220.

Winwood, P. C., \& Lushington, K. (2006). Disentangling the effects of psychological and physical work demands on sleep, recovery, and maladaptive chronic stress outcomes within a large sample of Australian nurses. Journal of advanced nursing, 56(6), 679-689.

Kristensen, T. S., Borritz, M., Villadsen, E., \& Christensen, K. B. (2005). The Copenhagen Burnout Inventory: A new tool for the assessment of burnout. Work \& Stress, 19(3), 192-207.

Campos, J. A. D. B., Carlotto, M. S., \& Marôco, J. (2013). Copenhagen Burnout Inventory-student version: adaptation and transcultural validation for Portugal and Brazil. Psicologia: Reflexão e Crítica, 26(1), 87-97. 